\title{
A NOVEL CONTROL METHOD TO PREVENT REGENERATIVE BRAKING FAILURE AND MINIMIZE LOSS OF SYSTEM BASED ON SUPERCAPACITOR SERIES CONNECTED TO THE TRACTION INVERTER
}

\author{
ZHIHONG ZHONG, XIAOFAN WANG, SHUAI LIN, XIAOCHUN FANG, \\ ZHONGPIN YANG \& FEI LIN \\ Beijing Jiaotong University, China
}

\begin{abstract}
At present, supercapacitor energy storage is widely used in urban rail transit. Supercapacitor energy storage is divided into stationary energy storage and on-board energy storage. Because there is no restriction of space and weight, stationary supercapacitor energy storage has developed rapidly in recent years. However, with the influence of no-load voltage, distance, braking power and other factors, stationary supercapacitor cannot fully absorb the residual regenerative braking energy in some special cases, it is necessary to configure a certain on-board supercapacitor to supplement it. Based on the existing stationary supercapacitor energy storage system, the article used a new on-board supercapacitor topology. The topology is series-connected to the traction inverter and consists of four IGBTs and one supercapacitor. The supercapacitor can be charged or discharged during traction and braking. The topology has no inductance and the volume is smaller than the traditional parallel topology. The topology utilizes inverter and motor overload capabilities to improve motor braking in high speed areas. Moreover, the losses of the DC side, inverter and motor are analyzed in detail. In the premise of meeting the capacity of storage, a control method which can minimize the total system loss is proposed based on the prediction of DC side current and motor side current. Finally, the simulation is carried out based on the actual parameters of Beijing Metro. Finally, based on the actual parameters of Beijing Subway, simulation is carried out. After using the series topology, on the one hand, with the ground storage equipment, braking resistance can be replaced completely to prevent train regeneration failure; on the other hand, after using the loss reduction algorithm, the traction system can reduce the loss of about $8 \%$.
\end{abstract}

Keywords: supercapacitor, on-board energy storage, topology, regeneration failure, minimizes the loss of traction drive system.

\section{INTRODUCTION}

In recent years, rail transit has developed rapidly, and since the urban rail train has the characteristics of frequent start-stop, large operation density and short distance between stations, the braking energy is considerable [1]. When the train regenerative braking, if there is no traction train adjacently to fully absorb the regenerative braking energy, the rest of the regenerative braking energy will make train braking traction network voltage exceed the permitted range, causing the train traction system overvoltage protection, leading to the regenerative braking failure. When regenerative braking fails, air braking will be put into use. In order to reduce the mechanical friction, by far the most common way is by car or excess of regenerative braking energy of the ground braking resistor in the form of heat release, but this way not only wastes the energy, also brings problems such as tunnel, the temperature rise [2].

In view of the effective utilization of regenerative braking energy, there are three main solutions [3]-[4]: energy saving operation optimization of multi-train, regenerative braking energy back grid and energy storage. Compared with the previous two methods, the advantage of energy storage mode is that the regenerative braking energy time attribute is 
given, namely, the time difference between the energy source and the energy demand side can exist. In addition, the energy storage device is not associated with ac power grid, and the system transformation complexity is low.

At present, the energy storage method has been widely used, have multiple line configuration for the stationary super capacitance of braking energy storage [5]-[7], such as our lab and Beijing subway operation co., ltd., Beijing urban construction design and development group co., ltd., and the car in the Qingdao sifang institute co., ltd., cooperation, super capacitor energy storage device developed along the metro batong line, played an obvious energy saving effect. But the vast majority of the current study is focused on the stationary supercapacitor energy storage, but due to the stationary supercapacitor energy storage by the no-load voltage, braking distance and braking power vehicle and energy storage device, the influence of such factors as hard in all cases to absorb all the surplus regenerative braking energy, in this paper, on the basis of the existing stationary supercapacitor energy storage, adopted a new type of on-board super capacitor energy storage topology, the topology than traditional topology of parallel type, without charging inductance, greatly reduced the volume [8]. Under the control strategy proposed in this paper, the on-board supercapacitors can completely replace the on-board brake resistance and completely prevent the regenerative braking failure. With the whole system, including circuit resistance, inverter loss and so on, the loss minimization is the goal, and the control mode is proposed to minimize the loss.

The first part of this paper is the introduction and explanation of series supercapacitor topology, and briefly introduces several working modes of the topology. The second part introduces the capacity configuration method of the series topology. The third part introduces the control method to minimize the system loss. The fourth part introduces the control strategy of preventing regenerative braking failure; The fifth part is related simulation analysis. After simulation analysis and verification, the control strategy proposed in this paper can completely prevent the occurrence of regenerative failure. On the other hand, it can minimize the loss of the system.

\section{TOPOLOGY INTRODUCTION}

It can be seen from the introduction, in order to improve the inverter side of the DC voltage to enhance the motor in the high-speed zone braking capacity, and consider the system lightweight design, this paper uses a super capacitor in series on the right side of the support capacitor. This paper uses the DC side of the series super capacitor topology is shown in Fig. 1.

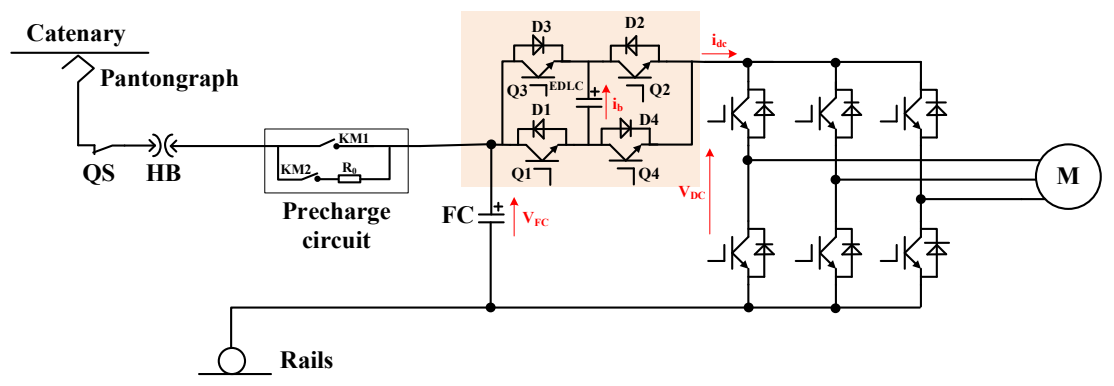

Figure 1: Series super capacitor topology. 
In the figure, $\mathrm{HB}$ is the high-speed circuit breaker, $\mathrm{FC}$ is the supporting capacitance, Q1, Q2, Q3 and Q4 are the IGBTs, D1, D2, D3 and D4 which control the charge and discharge of the super capacitor respectively, the anti-parallel diode, EDLC is super capacitor, M is the permanent magnet synchronous motor load. The topology has six modes of operation, the six working modes corresponding to the working state are shown in Fig. 2.

Voltage of supporting capacitor is $V_{\mathrm{FC}}$, Voltage of supercapacitor is $V_{\mathrm{C}}$, DC Voltage is Vdc.

1. In mode (a) and (d), $V_{\mathrm{dc}}=V_{\mathrm{FC}}-V_{\mathrm{c}}$, , inverter operates in buck mode.

2. In mode (b) and (c), $V_{\mathrm{dc}}=V_{\mathrm{FC}}+V_{\mathrm{c}}$, , inverter operates in boost mode.

3. In mode (e) and (f), $V_{\mathrm{dc}}=V_{\mathrm{FC}}$, inverter operates in standby mode.

\section{CAPACITY CONFIGURATION CONSIDERING VOLTAGE AND CURRENT CHANGES}

Unlike parallel topology can adjust the charge and discharge current, the series of topology shall not adjust the charge and discharge current, so it can absorb energy is closely related to the voltage of the dc side current, and its own, assuming the super capacitance infinity, then the topology of the super capacitor can absorb the maximum regenerative braking energy as shown in eqn (1)

$$
E_{\max }=\frac{U_{e}}{U_{d c}+U_{e}},
$$

where $U_{\mathrm{dc}}$ is the holding capacitor voltage before the tandem supercapacitor is put in, and $U_{\mathrm{e}}$ is the supercapacitor terminal voltage.

However, in practice, the maximum energy that can be stored is affected by the capacitance and the maximum voltage because the voltage of the supercapacitor varies with the charging and discharging in real time.

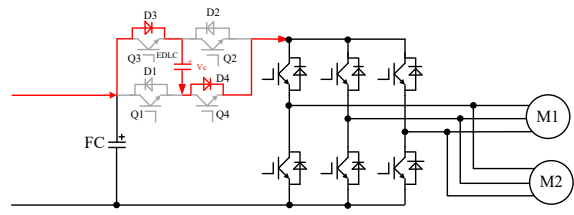

(a) Traction-charge

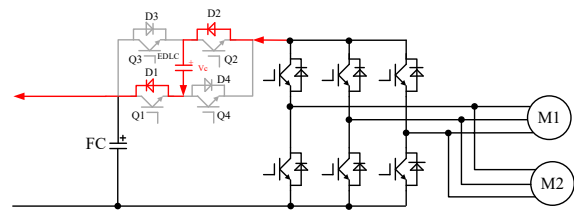

(c) Brake-charge

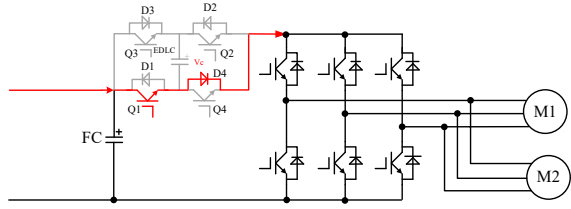

(e) Traction-idle

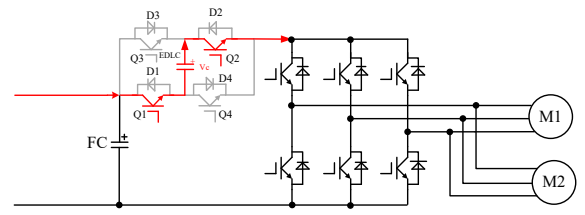

(b) Traction-discharge

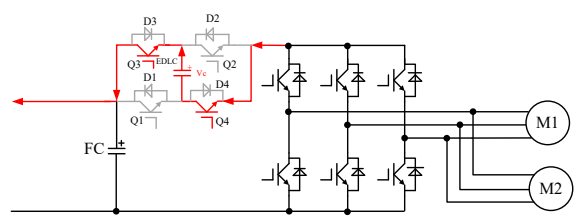

(d) Brake-discharge

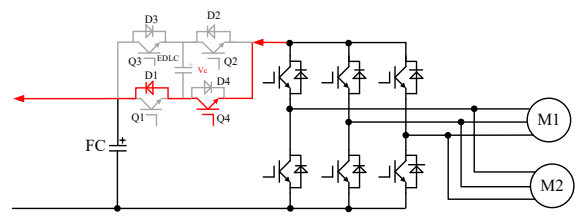

(f) Brake-idle

Figure 2: Six working modes circuit diagram. 
The relationship between the voltage and the current on both sides of the capacitor is shown in eqn (2)

$$
i=C \frac{d u}{d t}
$$

The relationship between the voltage and time can be written as follows, where $U_{0}$ is the maximum voltage of the supercapacitor

$$
u=\frac{i}{C} t+\frac{2}{U_{0}} .
$$

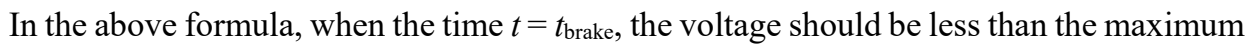
voltage of the super capacitor, that is.

$$
\frac{i}{C} t_{\text {brake }}+\frac{2}{U_{0}} \leq U_{0} .
$$

By multiplying the voltage of equation (3) by the current and integrating the time, the following constraint can be obtained

$$
\frac{i^{2}}{2 C} t_{\text {brake }}^{2}+\frac{U_{0} i}{2} t_{\text {brake }} \geq E_{\text {brake }}-E_{m} .
$$

Another constraint is the demand for absorbed energy, as shown in eqn (6), where $E_{\mathrm{m}}$ is the energy that can be absorbed by the ground-based supercapacitor.

$$
\frac{1}{2} C U_{0}^{2}-\frac{1}{2} C\left(\frac{U_{0}}{2}\right)^{2}=\frac{3}{8} C U_{0}^{2} \geq E_{\text {brake }}-E_{m}
$$

According to the two equations, we can calculate the approximate range of $U_{0}$ and C.

\section{THE LEAST LOSS ALGORITHM}

As the supercapacitor is put into use, the DC voltage can be increased or decreased within a certain range, in the traction or braking mode, the supercapacitor in many cases can choose more conditions. In the past, the choice of working conditions is only when the traction capacity is insufficient to discharge with a supercapacitor; when the braking energy is too much, a supercapacitor is used to charge. Studying the working condition without considering traction / braking performance and the loss of DC side, inverter and motor. This paper aims at reducing the loss of the traction drive system and improving traction / braking performance, a control approach of supercapacitor is proposed. An analysis of DC side, inverter and motor is carried out.

\subsection{DC side loss}

In the DC side, the dissipative elements are line resistance, switching devices and inherent resistance of the supercapacitor.

Assuming in one sampling period $\mathrm{T}_{\mathrm{s}}$, the voltage and current are constant, the loss of the line resistance can be calculated as the following equation

$$
E_{\text {line }}=i_{d c}^{2} * R_{\text {line }} * T_{s}
$$


The loss of supercapacitor's inherent resistance can be calculated as the following equation

$$
E_{\text {edlc }}=i_{c}^{2} * R_{e d l c} * T_{s}
$$

In the supercapacitor topology in Fig. 1, few switching states make the switching loss negligible, so we only calculate the IGBT and its anti-paralleled diode's on-state loss.

In one sampling period $T_{s}$, the on-state loss of IGBT and its diode can be calculated use eqns (9) and (10).

$$
\begin{gathered}
E_{\text {con-igbt }}=i_{d c}^{2} * R_{i g b t} * T_{s}, \\
E_{\text {con-dio }}=i_{d c} * V_{S D} * T_{s} .
\end{gathered}
$$

Notes: $E_{\text {line }}-$ the loss of the line, $i_{d c}$ - line current, $R_{\text {line }}$ - line resistance, $T_{s}$ - sampling time, $E_{\text {edlc }}$ - the loss of the supercapacitor, $i_{\text {edlc }}$ - supercapacitor's current, $R_{\text {edlc }}-$ supercapacitor's inherent resistance, $E_{\text {con_igbt }}-$ IGBT's conducting loss, $E_{\text {con-dio }}-$ Diode's conducting loss, $R_{i b g t}$ - IGBT's on-state resistance, $V_{S D}$ - Diode's forward voltage。

\subsection{Loss of the inverter}

In a carrier cycle, the current variation is very small, because the AC side is connected with the load, the current can be regarded as the output current.

The loss of the top IGBT and the bottom anti-paralleled diode is:

$$
\begin{aligned}
& P_{c o n \_i g b t}=\frac{R_{d s} I_{m}^{2}}{2 \pi}\left(\frac{\pi}{4}+\frac{2 m \cos \varphi}{3}\right), \\
& P_{\text {con_dio }}=\frac{V_{S D} I_{m}}{2 \pi}\left(1-\frac{m \pi \cos \varphi}{4}\right) .
\end{aligned}
$$

For other two legs, repeating the above process, we can get the total loss of the inverter

$$
P_{\text {con }}=3\left(2 P_{\text {con_igbt }}+2 P_{\text {con_dio }}\right) \text {. }
$$

The loss of the switching device can be expressed as below

$$
P_{s w \_i g b t}=f_{\text {out }} \sum_{n=1}^{N}\left[E_{\text {on }}(t)+E_{\text {off }}(t)\right]
$$

Notes: $R_{d s}$ - the conducting resistance of IGBT, $V_{S D}$ - the forward voltage of diode. $E_{o n}(t)$, $E_{\text {off }}(t)$ - turn on and turn off loss; $f_{\text {out }}$ - output frequency; $N=f_{s} / f_{\text {out }}$.

When $\mathrm{N}$ is sufficiently large (i.e., the carrier frequency is much larger than the fundamental frequency. Integrating equation (14), only calculate the positive current, then we can get the switching loss as below

$$
P_{s w_{-} i g b t}=\frac{f_{s}}{2 \pi} \int_{0}^{\pi}\left[E_{\text {on }} \cdot \frac{V_{\text {out }}}{V_{n}} \cdot \frac{I_{m} \sin (\omega t)}{I_{n}}+E_{\text {off }} \cdot \frac{V_{\text {out }}}{V_{n}} \cdot \frac{I_{m} \sin (\omega t)}{I_{n}}\right] d(\omega t) .
$$

Thus, the total loss of a three-phase inverter is

$$
P_{s w}=6 P_{s w_{-} i g b t} .
$$




\subsection{Loss of the motor}

The input power of the motor is

$$
\begin{aligned}
P_{i n} & =u_{d} i_{d}+u_{q} i_{q}=\left(R_{s} i_{d}-\omega L_{q} i_{q}\right) i_{d}+\left(R_{s} i_{q}+\omega\left(\varphi_{f}+L_{d} i_{d}\right)\right) i_{q} \\
& =R_{s}\left(i_{d}{ }^{2}+i_{q}{ }^{2}\right)+\omega\left(\varphi_{f} i_{q}+\left(L_{d}-L_{q}\right) i_{d} i_{q}\right)=P_{\text {loss }}+P_{e}
\end{aligned}
$$

Notes: $P_{\text {in }}-$ input power; $u_{d} u_{q}-\mathrm{dq}$ axis voltage; $i_{d} i_{q}-\mathrm{dq}$ axis current; $L_{d} L_{q}-\mathrm{dq}$ axis inductance; $R_{\mathrm{s}}$ - stator resistance, $w$ - angular velocity; $\varphi_{f}$ - permanent flux; $P_{\text {loss }}-$ loss of the motor; $P_{e}$ - electromagnetic power of the motor.

Neglecting the stray loss, the loss of the motor in one sampling period can be expressed as below

$$
E_{\text {motor }}=P_{\text {loss }} * T_{s}=R_{s}\left(i_{d}^{2}+i_{q}^{2}\right) T_{s}
$$

\subsection{Predictive current control}

The current prediction is carried out from two aspects. One is the prediction of dc-side current, the other is the prediction of motor current.

For the first aspect, the input power is kept constant, and if the supercapacitor is in the boost state at this time, the following equation

$$
V_{D C} i_{d c}=\left(V_{D C}-V_{c}\right) i_{d c 1}=\left(V_{D C}-2 V_{c}\right) i_{d c 2} .
$$

The $i_{\mathrm{dc} 1}$ and $i_{\mathrm{dc} 2}$, respectively, for the removal of super capacitor and super capacitor using buck current mode.

If the super capacitor is in the buck state at this time, the following equation is satisfied

$$
V_{D C} i_{d c}=\left(V_{D C}+V_{c}\right) i_{d c 3}=\left(V_{D C}+2 V_{c}\right) i_{d c 4} .
$$

The $i_{\mathrm{dc} 3}$ and $i_{\mathrm{dc} 4}$ are the current that used to remove the super capacitor and the super capacitor adopts the current under the boost mode.

If the super capacitor is not working at this time, the following equation is satisfied

$$
V_{D C} i_{d c}=\left(V_{D C}+V_{c}\right) i_{d c 5}=\left(V_{D C}-V_{c}\right) i_{d c 6} .
$$

The $i_{\mathrm{dc} 5}$ and $i_{\mathrm{dc} 6}$ at this time are the current that super capacitor in the boost mode and under the buck mode.

Therefore, the predictive ammeter of $i_{d c}$ is shown in Table 1.

Table 1: Predictive current of IDC

\begin{tabular}{cccc}
\hline $\begin{array}{c}\text { Now } / \text { Next } \\
\text { moment }\end{array}$ & Boost Mode & Buck Mode & Standby Mode \\
\hline Boost Mode & --- & $V_{\mathrm{DC}} i_{\mathrm{dc}} /\left(V_{\mathrm{DC}}-2 V_{\mathrm{c}}\right)$ & $V_{\mathrm{DC}} i_{\mathrm{dc}} /\left(V_{\mathrm{DC}}-V_{\mathrm{c}}\right)$ \\
Buck Mode & $V_{\mathrm{DC}} i_{\mathrm{dc}} /\left(V_{\mathrm{DC}}+2 V_{\mathrm{c}}\right)$ & --- & $V_{\mathrm{DC}} i_{\mathrm{dc}} /\left(V_{\mathrm{DC}}+V_{\mathrm{c}}\right)$ \\
Standby Mode & $V_{\mathrm{DC}} i_{\mathrm{dc}} /\left(V_{\mathrm{DC}}+V_{\mathrm{c}}\right)$ & $V_{\mathrm{DC}} i_{\mathrm{dc}} /\left(V_{\mathrm{DC}}-V_{\mathrm{c}}\right)$ & --- \\
\hline
\end{tabular}


For the second aspect, under the MTPA control, the motor runs at the intersection of the constant torque curve and the MTPA curve. For convenience calculations, the MTPA curve is linearized, the constant torque equation and the MTPA linear equation are shown in eqns (22) and (23)

$$
\begin{gathered}
T_{e}=1.5 P_{n}\left(\varphi_{f} i_{q}+\left(L_{d}-L_{q}\right) i_{d} i_{q}\right), \\
i_{d}=k i_{q},
\end{gathered}
$$

where $P_{n}$ is the pole pair of the motor and $k$ is the slope of the MTPA linear curve.

The solution of the equation is as follows, that is, under MTPA control, $i_{\mathrm{d}}$ and $i_{\mathrm{q}}$ are as follows

$$
\left\{\begin{array}{l}
i_{q}=\frac{\sqrt{\psi_{f}^{2}+\frac{8\left(L_{d}-L_{q}\right) k T_{e}}{3 P_{n}}}-\psi_{f}}{2\left(L_{d}-L_{q}\right) k} \\
i_{d}=k i_{q}
\end{array}\right.
$$

Under the control of a single current loop, the motor runs at the intersection of the constant torque curve and the voltage limit circle. The equation of the voltage limit circle is shown below

$$
\left(L_{q} i_{q}\right)^{2}+\left(L_{d} i_{d}+\psi_{f}\right)^{2}=\left(\frac{U_{s \max }}{\omega_{r}}\right)^{2} .
$$

Since the constant torque equation and the voltage limit circle equation are connected to the quadratic equation, there is no single solution formula, and the on-line solution is more difficult. Therefore, if the MTPA is controlled from the MTPA to the field weakening, Into the weak magnetic field, through the measured value at this time and the predicted MTPA state current comparison, to calculate the minimum loss at this time, select the state of the super capacitor at this time.

The switching process for the entire process control flow and the switchable conditions is shown in Fig. 3 and Fig. 4.

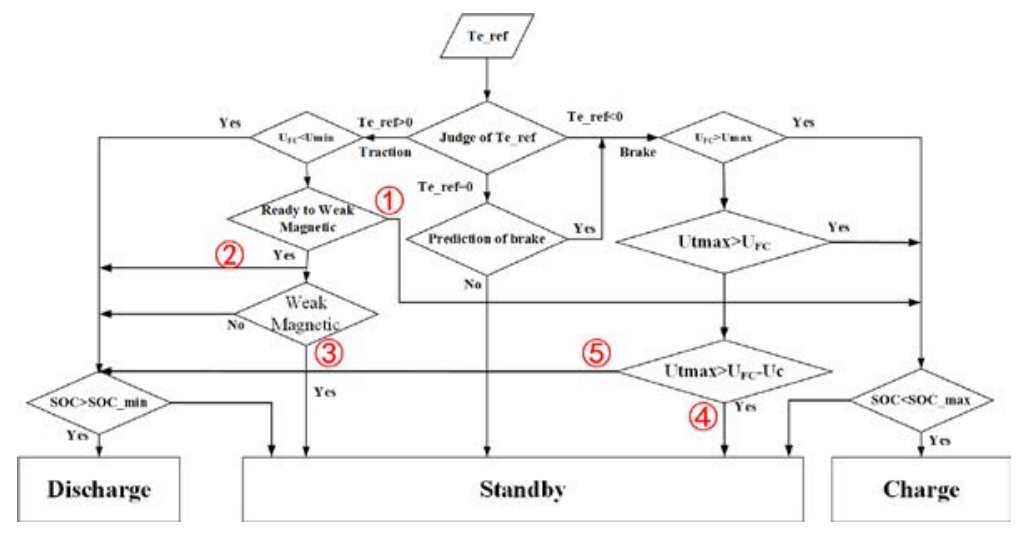

Figure 3: Overall control strategy under current prediction control. 


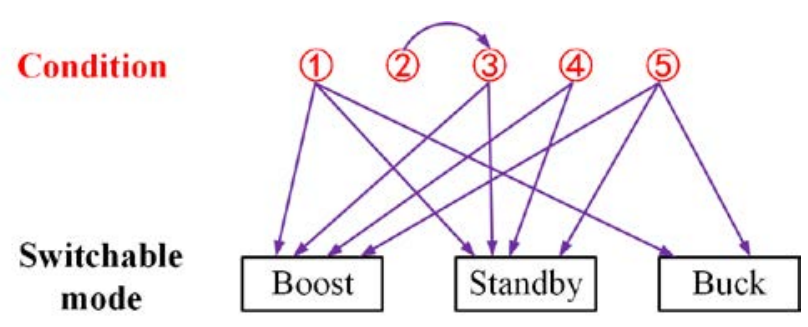

Figure 4: Predictive working conditions and its corresponding transition modes.

As shown in Fig. 4, when the operating conditions are predicted, the current is predicted, and the other conditions are not predicted. The predictable mode for each case is shown in the figure. After the prediction, the switchable mode can be compared with the loss mode, and the mode with the least loss is selected.

In order to reduce the loss at the same time will not significantly increase the switching device switching times, in the loss of contrast, the current state of the loss value to do a proportional adjustment.

\section{CONTROL METHOD TO PREVENT REGENERATION FAILURE}

In order to prevent the failure of regenerative braking, it is necessary to ensure that the energy which can be absorbed by the vehicle energy storage device during the remaining braking time is greater than the energy cannot be absorbed by the stationary energy storage device.

Super capacitor current can be expressed as follows

$$
i=C \frac{d u}{d t}=\frac{P}{U_{d c}+U_{e}} .
$$

The voltage and time of the integral items are placed on both sides of the left and right, can be integrated to obtain eqn (27)

$$
\left.\frac{C}{P}\left(U_{d c} \cdot u+\frac{1}{2} u^{2}\right)\right|_{u_{0}} ^{u_{1}}=\left.t\right|_{t_{0}} ^{t_{1}}=\Delta t
$$

$u_{0}$ is the supercapacitor voltage at the current moment, $\Delta \mathrm{t}$ is the remaining time of braking, $\mathrm{P}$ is the input power of the inverter, and $u_{1}$ can be solved according to eqn (27) as follows

$$
u_{1}=\sqrt{\left(U_{d c}+u_{0}\right)^{2}+\frac{2 P}{C} \Delta t} .
$$

Define $E_{1}$ as the maximum energy that the on-board supercapacitor can absorb at this moment, $E_{1}$ can be calculated as follows

$$
E_{1}=\frac{1}{2} C u_{1}^{2}-\frac{1}{2} C u_{0}^{2} .
$$

Define $E_{2}$ as the energy that cannot be absorbed by the stationary energy storage device at this moment, and the calculation is as follows

$$
E_{2}=E_{s}-E_{e s s}
$$


where $E_{\mathrm{s}}$ is the residual regenerative braking energy, $E_{\text {ess }}$ is the ground energy storage device can absorb energy.

The loss reduction algorithm of the previous section can be used when both of the following conditions are met at the same time; otherwise, the on-board energy storage device is forced to boost mode. Where $U_{0}$ is super capacitor terminal voltage

$$
\left\{\begin{array}{l}
u_{1}<U_{0} \\
E_{1}>E_{2}
\end{array} .\right.
$$

\section{SIMULATION ANALYSIS}

The simulation motor parameters are shown in Table 2.

$R_{\mathrm{S}}$ is the stator resistance, $R_{\mathrm{r}}$ is the rotor resistance, $L_{\mathrm{m}}$ is the magnetizing inductance, $L_{\mathrm{s}}$ is the stator inductance, $L_{\mathrm{r}}$ is the rotor inductance, and $T_{\mathrm{r}}$ is the rotor time constant.

In accordance with the Beijing Batong traction characteristic curve conversion, simulation of the train inertia design for $2 \mathrm{~kg} \cdot \mathrm{m}^{2}$.

Ignoring factors such as the friction in actual operation, the energy generated by braking in this simulation is as follows:

$$
E_{\text {brake }}=\frac{1}{2} J w^{2}=0.00439 \mathrm{kWh} .
$$

In simulation, the substation output voltage is set to $540 \mathrm{~V}$, and because the boost circuit according to the actual work, the boost ratio is best controlled within 3 , the minimum voltage of the super capacitor is set at $180 \mathrm{~V}$. Super capacitor discharge depth is generally controlled at $50 \%$, so the maximum supercapacitor voltage is $360 \mathrm{~V}$.

$$
E_{\text {brake }}=\frac{1}{2} C U_{\max }^{2}-\frac{1}{2} C U_{\min }^{2} .
$$

From the above equation, $\mathrm{C}=0.32 \mathrm{~F}$ can be solved. In this paper, it is hoped that the onboard supercapacitor can share about $10 \%$ of the stored energy, and since the energy transfer process has a small loss, the capacitance of the ground supercapacitor is configured as $\mathrm{C}_{0}=$ $0.26 \mathrm{~F}$.

It can be seen from the simulation below that in this case, the ground super capacitor cannot absorb all the regenerative energy. In order to prevent the DC voltage from exceeding the limit value, the braking resistor has been started.

In the simulation, the on-board braking resistor is required to absorb $10 \%$ of the residual regenerative braking energy. The braking time in the simulation is $8 \mathrm{~s}$ and the average current during braking is $2 \mathrm{~A}$. The maximum voltage of the supercapacitor is $\mathrm{U} 0=140 \mathrm{~V}$.

Table 2: Motor parameters.

\begin{tabular}{|l|l|l|l|}
\hline Parameter & Value & Parameter & Value \\
\hline Rated Power & $5.5 \mathrm{~kW}$ & Rated Torque & $30 \mathrm{Nm}$ \\
\hline$n_{\mathrm{p}}$ & 2 & $R_{\mathrm{S}}$ & $1.9 \Omega$ \\
\hline$R_{\mathrm{r}}$ & $1.00968 \Omega$ & $L_{\mathrm{m}}$ & $0.430875 \mathrm{H}$ \\
\hline$L_{\mathrm{S}}$ & $0.447165 \mathrm{H}$ & $L_{\mathrm{r}}$ & $0.447165 \mathrm{H}$ \\
\hline$T_{\mathrm{r}}$ & 0.4429 & $J$ & $2 \mathrm{~kg} . \mathrm{m}^{2}$ \\
\hline
\end{tabular}




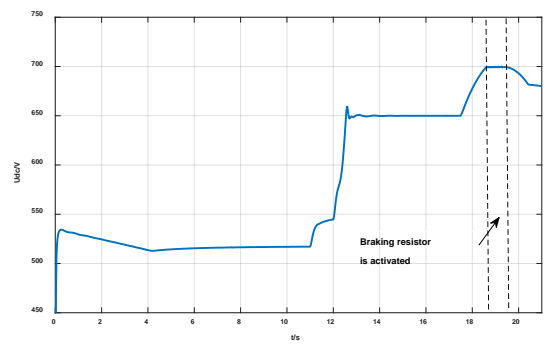

Figure 5: Traction network side voltage with braking resistor.

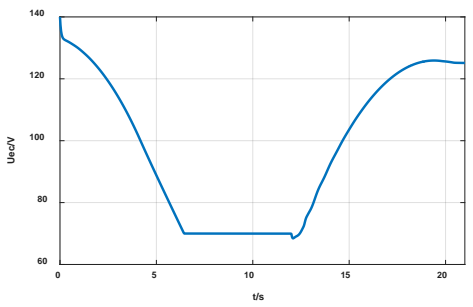

(a)

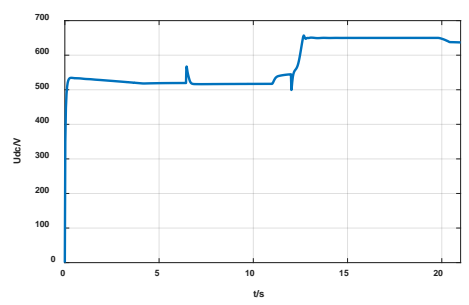

(b)

Figure 6: Super capacitor terminal voltage and traction network side voltage.

According to eqn (4) to eqn (6), the capacitance range of the car-mounted supercapacitor is as follows

$$
0.229 \leq C \leq 0.278
$$

Taking into account the energy-saving algorithm does not necessarily absorb energy at all times and taking into account the volume of the super capacitor, weight and other issues, take the median value of the capacitance $\mathrm{C}=0.25 \mathrm{~F}$.

It can be seen that after such configuration, if the car supercapacitor maintains the boost mode, the supercapacitor terminal voltage (a) and traction network side voltage (b) are as shown in the following figure, among them, $0 \sim 11 \mathrm{~s}$ for the traction process, $11 \sim 12 \mathrm{~s}$ for the inert process, $12 \sim 20 \mathrm{~s}$ for the braking process, train brake to 0 after $20 \mathrm{~s}$.

It can be seen that the vehicle absorbs energy of $0.5 * 0.25 *(1252-702)=1340.625 \mathrm{~J}$ during braking, and the total braking energy is $0.00439 \mathrm{kWh}=11804 \mathrm{~J}$, which roughly absorbs $12 \%$ of the total braking energy. It can also be seen that when the train is braked, the braking resistor is no longer started and the traction grid voltage is stable at $650 \mathrm{~V}$.

In the above configuration, the energy-saving algorithm is verified. Take the line resistance of $4 \Omega$ (due to the simulation current is small, and the inverter switching loss has nothing to do with the current, in order to fair comparison, so the line resistance is properly amplified), the internal resistance of the capacitor is $0.1 \Omega$. The model number of the inverter in the simulation is Infineon-FD400R33KF2C. Refer to the product manual. The inverter has a turn-on loss of $0.47 \mathrm{~J}$ and a turn-off loss of $0.43 \mathrm{~J}$. Under this parameter, the voltage of the on-board supercapacitor changes is shown in Fig. 7(a). Before and after the energy-saving algorithm is used, the system loss comparison chart is shown in Fig. 7(b) 


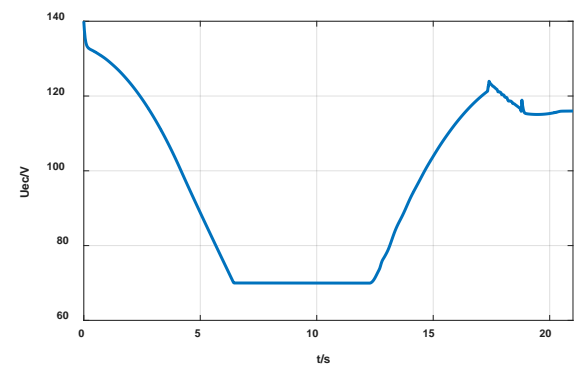

(a)

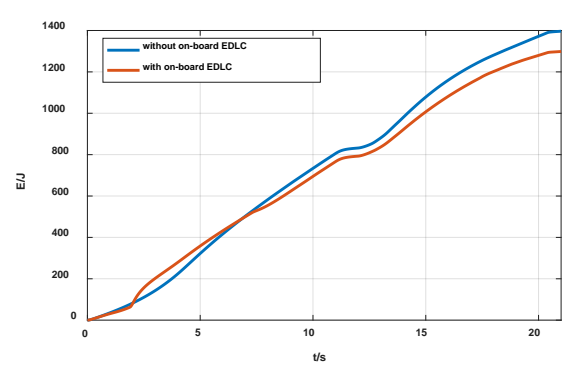

(b)

Figure 7: Supercapacitor voltage under energy-saving algorithm and losses comparison

$0 \sim 6.4 \mathrm{~s}$ is the traction boost state, due to the large traction current, the line loss accounted for most of the overall loss, the use of boost mode to reduce the current down is the most energy-efficient solution; 6.4 11s is the traction stand-by state, In the traction standby state and traction depressurization state, the traction standby state is a more energy-saving scheme; $11 \sim 12 \mathrm{~s}$ for the train idling, so that the super capacitor standby; 12 17.4s for the brake boost state, this time the braking current is relatively large, the line loss accounted for most of the overall loss, the energy-saving algorithm, the use of boost mode to reduce the current down is the most energy-efficient solution; With the braking current is reduced. During the period of $17.4 \mathrm{~s} \sim 19.2 \mathrm{~s}$, the buck mode is the most energy-saving scheme under the energy-saving algorithm. The supercapacitor discharges and the voltage decreases. The standby mode is between 19.2s and 20s. And through Fig. 7(b), it can be seen that the system loss is reduced by $100 \mathrm{~J}$ and the loss is reduced by $7.1 \%$.

As the train runs, the line resistance of the train changes and the change in supercapacitor voltage as the system resistance of the line resistance changes varies as shown below.

$\mathrm{R}_{\mathrm{L}}$ is the line resistance, we can see that under the energy-saving algorithm, as the line resistance decreases, the boost mode takes less and less time in the entire traction braking process. Figs 9 and 10 below, respectively, are histograms of losses that can be reduced with reduced line resistance, energy-saving algorithms, and histograms of percentages of total braking energy absorbed by the car's supercapacitors.

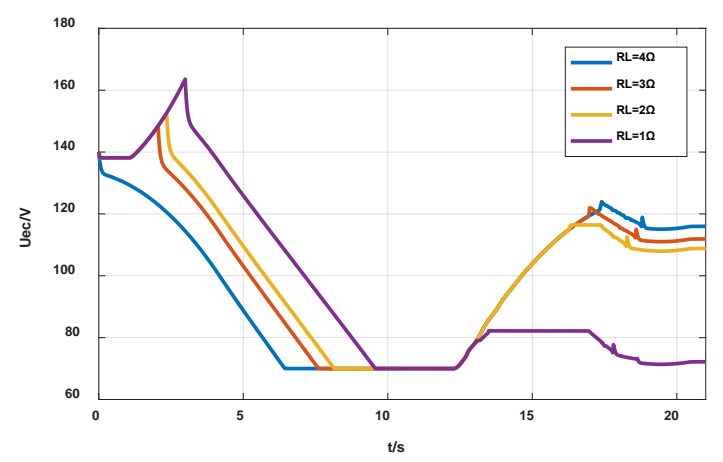

Figure 8: On-board supercapacitor voltage under line impedance changes. 


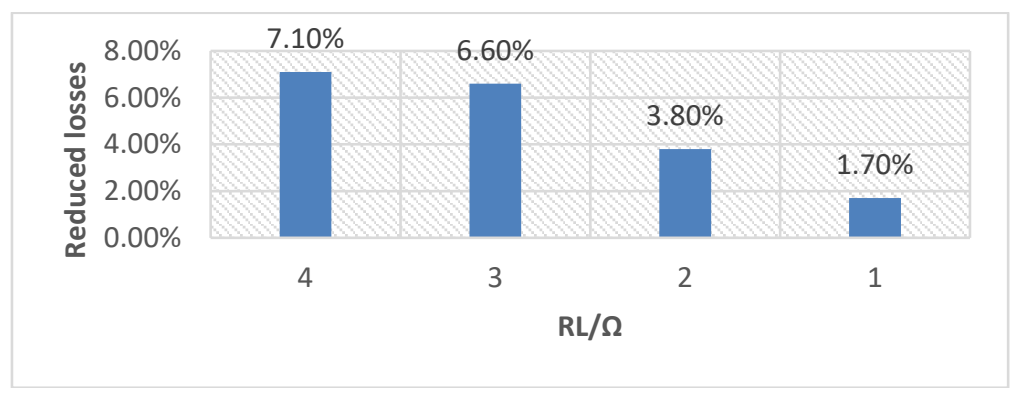

Figure 9: Losses reduced by energy-saving algorithm.

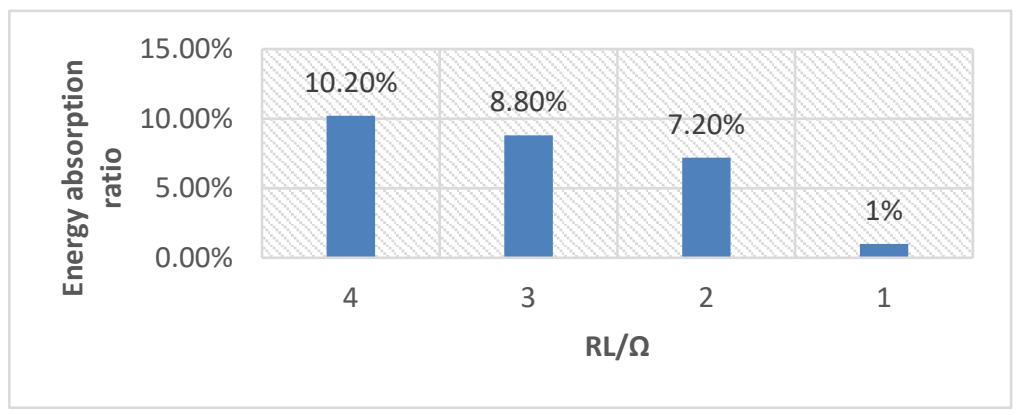

Figure 10: On-board super capacitor can absorb the percentage of total braking energy.

As can be seen, when the line resistance is small, if the control algorithm of antiregeneration failure is not adopted, the sufficient energy cannot be absorbed and the voltage of the traction network may surge so that regeneration failure may occur in serious cases. When $\mathrm{R}_{\mathrm{L}}=1 \Omega$, Fig. 11(a) and 11(b) below, respectively, are using anti-regeneration failure algorithm before and after the on-board supercapacitor voltage and DC voltage waveform.

It can be seen that before the anti-regeneration failure algorithm is adopted, the voltage on the DC side starts to rise around $17 \mathrm{~s}$ and approaches $700 \mathrm{~V}$. After the anti-regeneration failure algorithm is applied, the situation is suppressed and the DC voltage is stabilized at $650 \mathrm{~V}$.

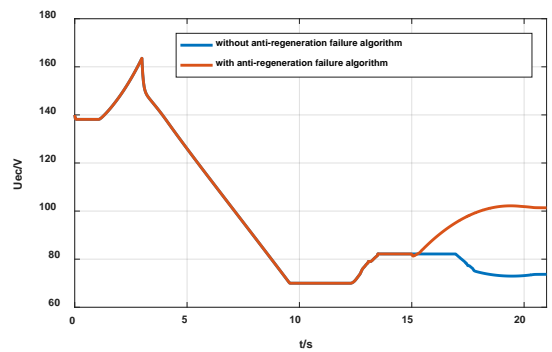

(a)

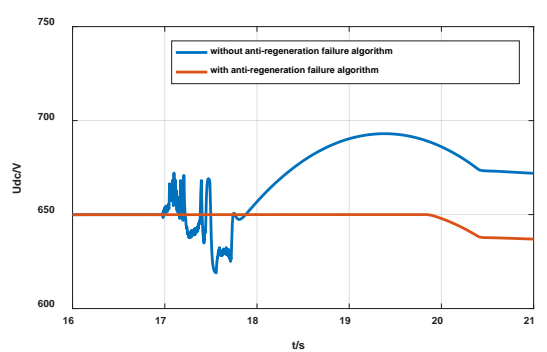

(b)

Figure 11: On-board supercapacitor voltage and traction network side voltage. 


\section{CONCLUSION}

In this paper, a new topology of on-board supercapacitors is adopted, which greatly reduces the weight and volume of on-board supercapacitor systems. A control method based on coordinated control of stationary supercapacitor is proposed, which can completely replace the on-board braking resistor and prevent regeneration failure. Based on the current predictive control, an energy-saving algorithm that minimizes the loss of the entire traction drive system is proposed. The simulation results show that the system loss can be reduced by about $8 \%$ at the maximum.

\section{REFERENCES}

[1] Palacin, R. et al., A systems approach to reduce urban rail energy consumption. Energy Conversion and Management, 80, pp. 509-524, 2014

[2] Bin, L., Application analysis of medium voltage power feed device in urban rail transit power supply system. Electrical Engineering, 3, pp. 148-151, 2016.

[3] Jianbing, F., On the utility of regenerating-brake energy. Urban Mass Transit, pp. 46$50,2007$.

[4] Jian Jun, Z., Braking energy analysis and regeneration technology of subway. Urban Mass Transit, pp. 33-36, 2006.

[5] Bilbao, E. et al., Optimal energy management strategy of an improved elevator with energy storage capacity based on dynamic programming. IEEE Transactions on Industry Applications, 50(2), pp. 1233-1244, 2014.

[6] Miyatake, M. \& Matsuda, K., Optimal speed and charge/discharge control of a train with on-board energy storage devices for minimum energy operation. Power Electronics, Electrical Drives, Automation and Motion, 2008. SPEEDAM 2008. International Symposium, pp. 1211-1216, 2008.

[7] Teymourfar, R. et al., Stationary super-capacitor energy storage system to save regenerative braking energy in a metro line. Energy Conversion and Management, pp. 206-214, 2012.

[8] Hirokazu, M. \& Yasuhiko, N., Variable-form carrier-based pwm for boost-voltage motor driver with a charge-pump circuit. IEEE Transactions on Industry Electronics, 62(8), pp. 4728-4738, 2015. 